\title{
Environmental and evolutionary effects on horn growth of male bighorn sheep
}

Mathieu Douhard ${ }^{1}$, Gabriel Pigeon ${ }^{1}$, Marco Festa-Bianchet ${ }^{1}$, David W. Coltman ${ }^{1,2}$, Simon Guillemette ${ }^{1}$ and Fanie Pelletier ${ }^{1}$

${ }^{1}$ Dépt de biologie et Centre d'Études Nordiques, Univ. de Sherbrooke, Sherbrooke, QC, J1K 2R1, Canada

${ }^{2}$ Dept of Biological Sciences, Univ. of Alberta, Edmonton, AB, T6G 2E9, Canada

Corresponding author: M. Douhard, Dépt de biologie et Centre d'Études Nordiques, Univ. de Sherbrooke, Sherbrooke, QC, J1K 2R1, Canada. E-mail:

mathieu.douhard@gmail.com

Decision date: $25-\mathrm{Nov}-2016$

This is the author manuscript accepted for publication and has undergone full peer review but has not been through the copyediting, typesetting, pagination and proofreading process, which may lead to differences between this version and the Version of Record. Please cite this article as doi: [10.1111/oik.03799]. 


\section{(Abstract)}

The development of male secondary sexual characters such as antlers or horns has substantial biological and socio-economic importance because in many species these traits affect male fitness positively through sexual selection and negatively through trophy hunting. Both environmental conditions and selective hunting can affect horn growth but their relative importance remains unexplored. We first examined how a large-scale climate index, the Pacific Decadal Oscillation (PDO), local weather and population density influenced both absolute and relative annual horn growth from birth to three years of male bighorn sheep Ovis canadensis over 42 years. We then examined the relative influence of environmental conditions and evolution mainly driven by trophy hunting on male horn length at three years of age. Horn growth was positively influenced by low population density and warm spring temperature, suggesting that ongoing climate change should lead to larger horns. Seasonal values of PDO were highly correlated. Horn growth increased with PDO in spring or summer at low density, but was weak at high density regardless of PDO. The interaction between population density and PDO in spring or summer accounted for a similar proportion of the observed annual variation in horn growth $(32 \%$ or $37 \%)$ as did the additive effects of spring temperature and density (34\%). When environmental conditions deteriorated, males allocated relatively more resources to summer mass gain than to horn growth, suggesting a conservative strategy favoring maintenance of condition over allocation to secondary sexual characters. Population density explained $27 \%$ of the variation in horn length, while evolutionary effects explained $9 \%$ of the variance. Thus, our study underlines the importance of both evolution and phenotypic plasticity on the development of a secondary sexual trait. 


\section{Introduction}

Climate and its expression through weather conditions are important determinants of life-history traits and population dynamics (Elton 1924, Krebs and Berteaux 2006). While early studies examined the effects of local weather variables, over the last two decades researchers have recognized the usefulness of large-scale indices such as the North Atlantic Oscillation (NAO, Hurrell 1995) to understand the influence of climate on plants and animals (Stenseth et al. 2002, Hallett et al. 2004, Stenseth and Mysterud 2005, Stige et al. 2006). Large-scale climate indices often explain more of the variation in life-history traits than local weather because they reduce the complexity of several weather components such as temperature, precipitation and wind into a single variable. The relationship between large-scale climate indices and local weather varies spatially (van de Pol et al. 2013), but our knowledge of how climate affects wildlife populations is biased towards Western Europe and Eastern North America where the effects of NAO are strong (Stenseth et al. 2002). Thus, we know little about the potential effects of Pacific climate indices on large herbivores in Western North America (Hebblewhite 2005, Loehr et al. 2010, Hegel et al. 2010).

As classic examples of sexually selected traits, antlers and horns of males in large polygynous herbivores offer a good opportunity to measure the influence of weather and climate on individual performance (Büntgen et al. 2014). These weapons evolved through sexual selection over access to females via male-male competition, female mate choice or both (Andersson 1994). Thus, horn size is a major determinant of dominance rank and mating success in adult males of some species (Coltman et al. 2002 and Martin et al. 2013 on bighorn sheep; Robinson et al. 2006 on Soay sheep Ovis aries; Bergeron et al. 2010 on Alpine ibex Capra ibex). Often, horn or antler growth indicates greater ability to obtain fitness-enhancing resources: male ibex growing large horn annuli in a given year have higher survival (von Hardenberg et al. 2004), the most

'This article is protected by copyright. All rights reserved.' 
fertile male red deer (Cervus elaphus) have the largest antlers (Malo et al. 2005), senescent male roe deer (Capreolus capreolus) with the largest antlers are the heaviest (Vanpé et al. 2007), and natural survival of yearling male bighorn sheep increases with early horn growth (Bonenfant et al. 2009a). Although several studies have reported that weather and climate can influence growth of horns (Table 1) and antlers (Smith 1998, Schimdt et al. 2001, Mahoney et al. 2001), we know little about the relative importance of genetics and plasticity on development of horns or antlers, or about how environmental conditions influence relative allocation of energy between body reserves and growth of these weapons.

Body mass shows substantial seasonal fluctuations in many temperate ungulates (Festa-Bianchet et al. 1996, Loison et al. 1999, Rughetti and Festa-Bianchet 2011). Summer mass gain determines the amount of resources available to survive winter (Pelletier et al. 2007). During summer, males therefore face a trade-off in allocation of resources between weapon growth and mass gain, particularly when environmental conditions are unfavorable. Festa-Bianchet et al. (2004) and Mysterud et al. (2005) showed that for a given mass, horn growth of lighter male bighorn sheep and antler growth of male red deer were reduced by decreasing resource availability, suggesting a conservative strategy that favors maintenance over allocation to secondary sexual characters. However, body mass does not provide a direct measure of mass gain during the period of horn or antler growth. Examination of the relationship between development of secondary sexual traits and mass gain during summer is challenging because it requires repeated measures of mass for the same animal.

Many studies investigating the effects of weather and climate on growth of horns or antlers used data from harvested animals (Table 1, Mysterud et al. 2005, Rivrud et al. 2013). The advantages of using harvest data often include a very large sample size and wide geographical coverage (Büntgen et al. 2014, Rivrud et al. 2013, Douhard et al. 2016). Harvested animals, however, are not a random sample of the population, as 
hunters usually select for certain morphological or behavioral traits (Ciuti et al. 2012, Pelletier et al. 2012, Leclerc et al. 2016). Artificial selection is particularly obvious in trophy hunting, where hunters seek males with large horns, antlers, or tusks, potentially leading to rapid evolutionary changes in horn growth (Coltman et al. 2003, Pigeon et al. 2016) and shape (Garel et al. 2007). Analyses of temporal changes in horn growth can identify potential evolutionary responses to selective hunting. In many cases, however, it is difficult to determine whether a decline represents an evolutionary response to trophy hunting or a plastic consequence of unmeasured environmental factors (Pérez et al. 2011, Douhard et al. 2016).

Here we investigate how annual horn growth, both absolute and relative to summer mass gain, varies with weather/climate conditions and population density in male bighorn sheep aged 0-3 years. We also compare the effects of environmental conditions to those of evolution, mainly driven by trophy hunting, on horn length at age 3 years. Our study on the intensively monitored sheep population at Ram Mountain, Alberta, Canada, spans 42 years, from 1972 to 2013. Males with large horns were subject to intense trophy hunting for the first 23 years of the study. Males with rapidly growing horns experience negative selection through trophy hunting several years before large horns improve reproductive success (Coltman et al. 2002). Horn length has a heritability of 0.39 and a decline in horn length and in breeding values of this trait until the hunt was stopped suggested an evolutionary response to trophy hunting (Pigeon et al. 2016). We do not know, however, whether climate and weather contributed to the decline in horn growth. Here we provide a unique quantification of the relative contributions of ecological and anthropogenic variables to the development of a secondary sexual character.

Based on previous studies (Table 1), we expected that spring temperature and precipitation would override other weather variables in driving variation in horn growth. Precipitation in spring should increase horn growth. We had no clear prediction about 
how spring temperature may affect horn growth, because a positive effect was reported for Alpine ibex (Giacometti et al. 2002, Büntgen et al. 2014), whereas a negative effect occurred for Alpine chamois (Chirichella et al. 2013). Because our study area is in western Canada, we used the Pacific Decadal Oscillation (PDO; Mantua et al. 1997) as a large-scale climate index. If PDO captures the overall fluctuations of relevant local weather variables, it should provide the best measure to explain annual variation in horn growth. However, if there is no correlation between PDO and local weather, we predicted a weak impact of PDO on horn growth. The effects of weather/climate can be modulated by population density (Bonenfant et al. 2009b), because both influence food availability and quality. We expected interactive effects of density and weather/climate on horn growth, as reported for juvenile survival in this population (Portier et al. 1998). Finally, we expected males to allocate more energy to mass gain than to horn growth under unfavorable conditions (Festa-Bianchet et al. 2004).

\section{Material and methods}

\section{Study area, population and sample collection}

Ram Mountain is about $30 \mathrm{~km}$ east of the Rockies in Alberta, Canada $\left(52^{\circ} \mathrm{N}, 115^{\circ} \mathrm{W}\right.$, elevation 1700-2200 m). Sheep are captured in a corral trap baited with salt from late May to late September, and marked using visual collars and plastic ear tags. Nearly all males (93\%) are first caught as lambs or yearlings so their exact age is known. The few males caught as adults (7\%) were aged by counting the horn annuli (see below).

Population density, measured as the number of females 2 years and older in June

(Jorgenson et al. 1998), varied markedly over the study through changes in removals, translocations and environmental conditions (Rioux-Paquette et al. 2011).

Horn growth continues throughout life, but varies with age and season. It occurs mainly from April to September (Bunnell 1978). Cessation of horn growth in winter creates an annulus, allowing measurement of each annual growth increment. Length of each increment was measured once to the nearest mm, usually in the year after it was 
formed. The yearly resighting rate of surviving males was $96 \%$ (Jorgenson et al. 1997) and about $90 \%$ of males were captured each year. Horns start to grow at about 10 weeks of age and most lambs are born in late May or early June (Feder et al. 2008). Hence, the first increment and part of the second develop before a male reaches 1 year of age. In our analyses, we considered annual horn increments 1 to 4 , which account for approximately $67 \%$ of asymptotic horn length (Bonenfant et al. 2009a). Measures of subsequent horn increments were biased towards smaller males up to 1996, because males with fast-growing horns were at risk of being shot from 4 years of age (FestaBianchet et al. 2004). The hunting season was from late August to the end of October. After 1996, a more restrictive definition of minimum horn curl for harvestable rams severely restricted the harvest, and the hunt was closed in 2011. Similar to Bonenfant et al. (2009a), we used the left horn measurement. A total of 832 horn annuli from 292 males were included in analyses $(131,53,41$ and 67 males with 4, 3, 2 and 1 increments measured, respectively).

\section{Climate and weather data}

We considered local weather variables (precipitation and average temperature) and PDO values in seasons of biological relevance to horn growth: winter (December-March), spring (April-May) and summer (June-September). Weather in spring and summer reflects conditions during horn growth. Loehr et al. (2010) found that climate in AprilMay had the greatest influence on horn growth of Dall sheep, a close relative of bighorn sheep. During winter horn growth stops, but winter weather can influence subsequent plant phenology (Post and Stenseth 1999) which, in turn, may affect growth the following spring-summer (Mysterud et al. 2001).

Precipitation (total rainfall plus water equivalent of total snowfall in $\mathrm{mm}$ ) and average temperature $\left({ }^{\circ} \mathrm{C}\right)$ were obtained from the Environment Canada meteorological station at Nordegg, about $20 \mathrm{~km}$ west of Ram Mountain. Unfortunately, weather data were missing for some seasons (see supplementary Appendix 1). PDO values

'This article is protected by copyright. All rights reserved.' 
(http://jisao.washington.edu/pdo) were available each year from 1972 to 2013. The PDO is measured as the leading principal component of monthly sea surface temperature in the North Pacific from $20^{\circ} \mathrm{N}$ poleward (Mantua et al. 1997). It is characterized by shifts between warm and cool phases over an interdecadal time-scale.

\section{Statistical analyses}

We first measured interdependence and the degree of correlation among all environmental variables using Pearson's correlation coefficients (r). We used regression analyses to identify any linear or quadratic temporal trends in each of the weather/climate variables. All statistical analyses were conducted using R version 3.1.2 (www.r-project.org). We considered an alpha-level level of $p=0.05$ as statistically significant for all analyses.

In all analyses of annual horn growth, we used linear mixed models with male identity as a random factor to account for repeated measurements of the same individuals. We fitted models with the 'Ime' function in the 'nlme' library using maximum likelihood (Pinheiro and Bates 2000). We tested the significance of male identity with likelihood ratio test (LRT). We also estimated repeatability, the proportion of variation in horn growth attributed to individual heterogeneity, as the ratio of individual variance to total variance (Nakagawa and Schielzeth 2010, see Toïgo et al. 2013 for an application). Horn growth was log-transformed in all models to obtain residuals with homogeneous variance.

We tested and quantified the amount of temporal variation in annual horn growth accounted for by each of the covariates climate, weather and population density using analysis of deviance (ANODEV; Skalski et al. 1993, Grosbois et al. 2008). The ANODEV compares the deviance of the covariate model $\left(\mathrm{M}_{\mathrm{cov}}\right)$ vs. both the baseline $\left(\mathrm{M}_{\mathrm{cst}}\right)$ and the full time dependent $\left(\mathrm{M}_{\mathrm{t}}\right.$, including year as a factor) models. The Anodev statistic $F_{\text {ndf,ddf }}$ is:

'This article is protected by copyright. All rights reserved.' 


\section{Fndf, ddf $=\frac{\frac{\text { Dey Mest }- \text { Dev Meov }}{\text { np Mrov - np Mcst }}}{\frac{\text { Dev Mcoy - Dev Mt }}{\text { np Mt - np Mcev }}}$}

where Dev and np are, respectively, the deviance and the number of parameters of the models. This statistic follows a Fisher-Snedecor distribution, where the number of degrees of freedom for the numerator (ndf) is $n p M_{c o v}-n p M_{c s t}$ and the number of degrees of freedom for the denominator (ddf) is $n p M_{t}-n p M_{c o v}$. The Anodev statistic is computed from individual-level data but it evaluates the impact of a covariate on annual variation in horn growth in the population. The baseline model varied between analyses but it always included a cubic effect of age (see supplementary Appendix 2) and population density when testing the effects of climate and weather covariates. Supplementary Appendix 3 contains R code for the ANODEV procedure. We tested the first-order interactions between climate/weather and density successively, and if not significant, the main effects of weather and climate. The $\mathrm{R}^{2}$ of the ANODEV quantifies the temporal variation in average horn growth accounted for by each covariate as follows:

\section{$\mathrm{R}^{2}$ aneder $=\frac{\text { Dev Mest }- \text { Dev Meov }}{\text { Dev Mest - Dey Mt }}$}

We re-ran $\mathrm{M}_{\text {cov }}$ models by standardizing all continuous variables (subtracting mean and dividing by standard deviation) and including year as a random effect. This procedure provided parameter estimates for covariates, which are directly comparable, unbiased and robust. Standardization does not affect ANODEV tests.

We used linear mixed models with male identity and year as random effects to assess whether the allometric relationship between annual horn growth and summer mass gain varied with environmental conditions. We built an index of environmental conditions of the current year using covariates that influenced horn growth (see Results). Summer mass gain was the difference between mass adjusted to 15 September and June 5 of the same year. Adjusted mass was obtained from repeated measurements 
of the same individual (see Martin and Pelletier 2011 for more details). Most males aged 0-3 years were captured at least twice each summer (Festa-Bianchet et al. 2004). Horn growth and summer mass gain were log-transformed prior to analysis to account for the allometric link (Houle et al. 2011).

A Bayesian animal model was used to quantity the relative contribution of environmental and evolutionary effects, including those induced by trophy hunting (Pigeon et al. 2016). The model partitions phenotypic variation into its components, including the additive genetic component (Wilson et al. 2010). We first considered an animal model for annual horn growth, but this trait showed very little heritability $\left(\mathrm{h}^{2}=\right.$ 0.001 , see appendix 4). Therefore, we used horn length at 3 years of age adjusted to September 15, a trait with significant heritability (see Results). All environmental covariates retained from the analyses on annual horn growth were included as fixed effects after appropriate transformation if necessary as detailed in Results. Similar to Pigeon et al. (2016), pedigree and year of birth were included as random effects. We estimated the proportion of variance in horn length accounted for by each environmental covariate as the difference between $\mathrm{R}^{2}$ of the full model and $\mathrm{R}^{2}$ of the model excluding that specific parameter using marginal $\mathrm{R}^{2}$ formulation (Nakagawa and Schielzeth 2013). To estimate the variance in horn length accounted for by annual changes in breeding values, we calculated the variance of annual mean breeding values of individuals alive in each year. Horn length variation explained by evolution and environmental factors was relative to the total variance in horn length. Animal models were run using MCMCglmm (Hadfield 2010) on three independent Markov chains for 2.6 million iterations with a burn-in of 100000 and a thinning of 2500 . The convergence of the model was assessed from visual inspection of the three independent Markov chains.

\section{Results}

\section{Correlation and temporal trend of environmental variables}

'This article is protected by copyright. All rights reserved.' 
Seasonal values of PDO were highly correlated (Table 2) and presented a quadratic temporal trend between 1972 and 2013, increasing up to the early 1990's then declining (Fig. 1, supplementary Appendix 1). Population density showed a similar trend over time, so that it was positively correlated with both $\mathrm{PDO}_{\text {spring }}$ and $\mathrm{PDO}_{\text {summer }}$ PDO was weakly linked to local weather: the only statistically significant relationships were between spring and winter PDO and spring temperature (Table 2). Average winter temperature increased by $0.08 \pm 0.03{ }^{\circ} \mathrm{C}$ per year from 1972 to 2013 , or $3.34^{\circ} \mathrm{C}$ overall, whereas winter precipitation decreased by $0.26 \pm 0.10 \mathrm{~mm} / \mathrm{year}$ for an overall decrease of $10.66 \mathrm{~mm}$, producing a negative correlation between these variables (Table 2). Average spring temperature varied from $1.2^{\circ} \mathrm{C}$ in 1982 to $6.4^{\circ} \mathrm{C}$ in 2006 and was positively correlated with winter temperature, but did not show a temporal trend. Average summer temperature increased by $0.04 \pm 0.03{ }^{\circ} \mathrm{C}$ per year from 1972 to 2013 , an overall increase of $1.6^{\circ} \mathrm{C}$. No temporal trend in summer and spring precipitation was detected (Fig. 1, supplementary Appendix 1).

\section{Annual horn growth variation}

In the mixed model of horn annual increment with age, male identity was highly significant (LRT between models with and without random effect $=20.26$, d.f. $=1, \mathrm{P}<$ $0.001)$. Repeatability was 0.17 : after accounting for age, $17 \%$ of variation in annual increments was attributed to individual differences. When including year as a random effect, repeatability fell to $10 \%$, suggesting that a large proportion of differences among individuals in annual horn growth was caused by inter annual differences in environment.

Considering local weather, we found that annual horn growth increased with spring temperature (Table 3, Fig. 2). There was no evidence that other weather variables influenced horn growth and we detected no interaction between weather and population density (Table 3). Horn growth decreased with increasing density. The additive effects

'This article is protected by copyright. All rights reserved.' 
of spring temperature and density accounted for $34 \%$ of annual variation in horn growth. Separately, spring temperature and density accounted for $11 \%$ and $17 \%$, respectively, of that variation.

Considering large-scale climate, we found that $\mathrm{PDO}_{\text {spring }}$ and density had interactive effects on horn growth (Table 3): $\mathrm{PDO}_{\text {spring }}$ had a positive effect at low density, whereas horn growth remained weak regardless of $\mathrm{PDO}_{\text {spring }}$ at high density (Fig. 3). Because $\mathrm{PDO}_{\text {spring }}$ and $\mathrm{PDO}_{\text {summer }}$ were highly correlated $(\mathrm{r}=0.67)$, we found a similar interaction for $\mathrm{PDO}_{\text {summer }}$ and density although there were few horn measurements when $\mathrm{PDO}_{\text {summer }}$ was high and population density low (Table 3, supplementary Appendix 5). Interactions between PDO in spring or summer and density accounted respectively for 32 and $37 \%$ of annual variation in horn growth. When interactions with density were ignored, PDO in summer or spring accounted for less than 1 and 4\%, respectively, of annual variation in horn growth. $\mathrm{PDO}_{\text {winter }}$ had no statistically significant effect on horn growth independent of population density (Table 3).

\section{Allometry between summer mass gain and horn growth}

We examined the effects of environment on the allometric mass-horn growth relationship by using an index of environmental conditions based on density and PDO in summer (Fig. 4). We found an interaction between environmental quality and summer mass gain on horn growth $(\mathrm{LRT}=8.95$, d.f. $=1, \mathrm{P}=0.002)$. When environmental conditions were poor, males with below-average summer mass gain grew less horn for a given mass gain (Fig. 4). For males achieving high summer mass gain, relative allocation to horn growth appeared independent of environmental conditions (Fig. 4). We found similar results when considering an index of environmental conditions based on density and spring temperature (supplementary Appendix 6). 


\section{Relative influence of evolution and environmental conditions on horn length}

Horn length at 3 years of age has a heritable component $\left(\mathrm{h}^{2}=0.36\right.$, see supplementary Appendix 4 for other variance components). The environmental variables entered in the full animal model were spring temperature and the interactive effects of density and $\mathrm{PDO}_{\text {summer }}$ experienced between 1 and 3 years of age. Both annual values of PDO and density were averaged during this period because of their high temporal autocorrelation, whereas spring temperatures from age 1 to 3 were included as separate fixed effects because they varied substantially from one year to the next (Fig. 1). We found that variability in horn length was mostly driven by population density (\% variance explained $=26.5, \mathrm{CI}=[2.6 ; 45.2])$ and evolutionary changes $(\%$ variance explained $=$ $8.8, \mathrm{CI}=[3.9 ; 22.2])$. Spring temperatures accounted for only $0.9 \%(\mathrm{CI}=[-23.1 ; 27.1])$ of variation in horn length. Compared with the effect of density alone, a model that also included $\mathrm{PDO}_{\text {summer }}$ and the interaction between $\mathrm{PDO}_{\text {summer }}$ and density explained only an additional $3 \%$ of the variation in horn length $(\%$ variance explained $=29.4, \mathrm{CI}=$ $[14.0 ; 50.2])$.

\section{Discussion}

We found that local weather effects on annual horn growth of male bighorn sheep are density-independent, whereas climate effects are mediated by an interaction with population density. Therefore, some effects of climate change may be missed by studies that ignore changes in population density (Bonenfant et al. 2009b). For example, a positive effect of spring/summer PDO on horn growth was apparent only at low density. High population density likely reduces the availability of forage through increased competition, slowing horn growth independently of PDO. An influence of PDO in April-May was also reported for horn growth of Dall sheep in the Yukon but the direction of the effect was not specified (Loehr et al. 2010). Large-scale climate indices

often predict variation in phenotypic traits and demographic parameters better than local

'This article is protected by copyright. All rights reserved.' 
weather variables (Post and Stenseth 1999, Hallett et al. 2004, Stenseth and Mysterud 2005, but see Knape and de Valpine 2011). In our study, the combined effects of density and PDO in spring or summer explained 32 and $37 \%$ of annual variation in horn growth, compared to $34 \%$ for the additive effects of density and spring temperature. Population density was the most important driver of annual variation in horn growth. Because the variance explained $\left(\mathrm{r}^{2}\right)$ in most ecological studies is $2.51-5.42 \%$ (Møller and Jennions 2012), our ANODEV models may appear to explain a high level of variance. However, many climate studies (Lourdais et al. 2004, Jensen et al. 2006) reported $\mathrm{r}^{2}$ measured at the individual level rather than at the level of year or cohort, where the proportion of variance explained is inevitably higher. Large-scale climate indices can be useful for highly mobile species such as caribou (Rangifer tarandus), where one single meteorological station cannot capture all relevant weather conditions (Stenseth and Mysterud 2005, Nielsen et al. 2012). Our study revealed the usefulness of PDO also for a more sedentary species. However, it is difficult to disentangle the effects of PDO in spring and summer on horn growth because they are highly correlated. Local variables, recorded at a smaller temporal scale, can help identify the critical time window during which weather influences the expression of life-history traits (Krebs and Berteaux 2006).

Considering local weather, we found that spring temperature positively influenced annual horn growth, accounting for $11 \%$ of its variation. However, spring temperature experienced during the first years of life accounted for less than $1 \%$ of the variation in horn length at 3 years of age, likely because most individuals encountered both poor and good conditions during their first three spring seasons, with little consistent effects on cumulative horn growth. By contrast, the effects of population density were likely cumulative because density varied little over any 3-year period (Marcil-Ferland et al. 2013). Warmer springs can promote earlier and more rapid snowmelt, leading to an earlier start of vegetation growth (Myneni et al. 1997, Pettorelli 
et al. 2005). The Rocky Mountains have very cold winters (Fig. 1), so most winter precipitation falls as snow. Alpine ungulates appear to show contrasting patterns in how spring weather influences growth traits. In agreement with our study, annual horn growth of male ibex increased with spring temperature (Giacometti et al. 2002, Büntgen et al. 2014) and antler size of male wapiti (Cervus canadensis) was positively correlated with March-April temperatures (Smith 1998). On the other hand, warm spring temperature or related variables often have negative effects on body growth or mass (Rughetti and Festa-Bianchet 2012 in Alpine chamois, Pettorelli et al. 2007 in mountain goats, Oreamnos americanus, and bighorn sheep, Douhard et al. 2013 in roe deer). On Ram Mountain, rapid plant maturation associated with warmer springs appeared to reduce lamb body growth (Pettorelli et al. 2007). These apparently contrasting results may arise from two factors: the trade-off between plant productivity and length of access to high-quality forage and likely differences in the timing of horn and mass growth. There is an allocation trade-off between quantity of plant tissue and nutritional quality (Seydack et al. 2012). Although rapid warming during green-up can increase plant productivity, it can also speed up maturation, shortening the period when forage is highly digestible (Albon and Langvatn 1992). Warm springs may also reduce spatial heterogeneity in the timing of vegetation green-up if they generate rapid and synchronous snowmelt over the landscape, decreasing the opportunity to access highquality forage during a long period (Mysterud et al. 2001, Pettorelli et al. 2007). Horns may benefit from warm temperatures in spring because they start growing at a high rate (Hemming 1969) and may be less affected than body growth by the subsequent rapid maturation of plant tissue. Recent studies have highlighted the potential pitfalls of extrapolating life-history responses to climate change at different locations or across species (Martínez-Jauregui et al. 2009, Tafani et al. 2013). We suggest that contrasting patterns can also emerge when considering multiple growth traits within a population. 
Although we found no temporal trend in average spring temperature, mean temperatures for all seasons are expected to increase in Canada (Bush et al. 2014). Horn growth of male bighorn sheep may thus increase under ongoing climate change, as reported for Alpine ibex (Büntgen et al. 2014). Climate change may also influence the relative allocation of resources to body and horn growth. Bighorn sheep can lose over $20 \%$ of autumn mass during winter (Festa-Bianchet et al. 1996) so that summer is critical to replenish reserves. The relationship between summer mass gain and horn growth was weak but varied according to environmental conditions. Males gaining little mass in summer reduced energy allocation to horn growth when environmental conditions deteriorated, possibly to increase chances of survival. Males achieving high summer mass gain grew as much horn under poor as under favorable environmental conditions, likely because increase allocation to mass does not influence their future survival. These results suggest that the conservative life-history tactics typical of adult female large herbivores are also selected for in males (see also Toïgo et al. 2013).

Factors affecting horn growth are not limited to ecological conditions. Human harvest is a strong selective pressure on morphological traits (Allendorf and Hard 2009). Horn size of harvested bighorn males in Alberta has declined over the last 4 decades (Festa-Bianchet et al. 2014), but large-horned rams appear to persist in protected areas where selective hunting does not occur (Pelletier et al. 2014). Evolutionary responses to trophy hunting are apparent in male bighorn sheep at Ram Mountain (Coltman et al. 2003, Pigeon et al. 2016). Measuring the relative influences of evolution and plasticity underlying phenotypic variation is challenging (Boutin and Lane 2014). Using an integral projection model (IPM), Ozgul et al. (2010) argued that temporal changes in body mass of yellow-bellied marmots (Marmota flaviventris) resulted from ecological (plastic) rather than evolutionary responses to environmental change. However, the use of IPMs as parameterized to date is problematic, because these models cannot detect evolutionary changes (Chevin 2015, Janeiro et al. in press). Our results suggest that 
population density was the major contributor to temporal variation of horn length, explaining about three times as much variance as evolutionary effects. While there was strong support for climate or weather effects in the analyses of annual horn growth, climate or weather covariates explained very little of the variation in horn length. We likely underestimated the evolutionary effects due to trophy hunting because the variance in breeding values encapsulates two opposing evolutionary forces: artificial selection favoring small horns and sexual selection favoring large horns. In addition, after the near-cessation of hunting in 1996, breeding values of horn length showed a weak tendency towards an increase (Pigeon et al. 2016). It is also important to note that our study population underwent a threefold change in density. A weaker effect of density should be expected in populations that have maintained more stable numbers, as is the case in much of the province of Alberta where selective hunting likely plays an absolutely similar, but proportionally much greater, effect on changes in horn size (Festa-Bianchet et al. 2014). Our research highlights the importance of considering the ecological, evolutionary and conservation implications of selective harvests (FestaBianchet 2003, Garel et al. 2007, Douhard et al. 2016). Humans are changing the world at an unprecedented rate, modifying phenotypic and genetic traits in wild populations through, for instance, climate change and selective harvests. Only continued long-term individual-based studies will enable the detection of these patterns, because they can quantify both environmental and evolutionary effects (Clutton-Brock and Sheldon 2010).

\section{Acknowledgments}

Animal-handling procedures were approved by the Animal Care Committee of the University of Sherbrooke (protocols MFB2009-01 and FP2012-01), affiliated to the Canadian Council on Animal Care. We thank A. Hubbs, C. Feder, J. Hogg and J. Jorgenson for their support of the Ram Mountain research program, and all assistants

'This article is protected by copyright. All rights reserved.' 
and students who worked on Ram Mountain over decades. This work was funded by a Natural Sciences and Engineering Research Council (NSERC) EnviroNorth post-

doctoral fellowship to M.D. M.F.B. and F.P. are funded by NSERC of Canada

Discovery Grants and by research grants from the Alberta Conservation Association.

F.P. holds the Canada Research Chair in Evolutionary Demography and Conservation.

We thank A. Mysterud, S. Albon and M. Morrissey for constructive comments on the manuscript. 


\section{References}

Albon, S. D. and Langvatn, R. 1992. Plant phenology and the benefits of migration in a temperate ungulate. - Oikos 65: 502-513.

Allendorf, F. W. and Hard, J. J. 2009. Human-induced evolution caused by unnatural selection through harvest of wild animals. - Proc. Natl Acad. Sci. USA 106: 99879994.

Andersson, M. B. 1994. Sexual selection. - Princeton University Press.

Bergeron, P. et al. 2010. Secondary sexual characters signal fighting ability and determine social rank in Alpine ibex (Capra ibex). - Behav. Ecol. Sociobiol. 64: 12991307.

Bonenfant, C. et al. 2009a. Age-dependent relationship between horn growth and survival in wild sheep. - J. Anim. Ecol. 78: 161-171.

Bonenfant, C. et al. 2009b. Empirical evidence of density-dependence in populations of large herbivores. - Adv. Ecol. Res. 41: 313-357.

Boutin, S. and Lane, J. E. 2013. Climate change and mammals: evolutionary versus plastic responses. - Evol. Appl. 7: 29-41.

Bunnell, F. 1978. Horn growth and population quality in dall sheep. - J. Wildl. Manag. 42: $764-775$.

Büntgen, U. et al. 2014. European springtime temperature synchronises ibex horn growth across the eastern Swiss Alps. - Ecol. Lett. 17: 303-313.

Bush, E. J. et al. 2014. An overview of Canada's changing climate. - In: Warren, F. J. and Lemmen, D. S. (eds.), Canada in a changing climate: sector perspectives on impacts and adaptation. Government of Canada, pp. 23-64.

Chevin, L.-M. 2015. Evolution of adult size depends on genetic variance in growth trajectories: a comment on analyses of evolutionary dynamics using integral projection models. - Methods Ecol. Evol. 6: 981-986.

'This article is protected by copyright. All rights reserved.' 
Chirichella, R. et al. 2013. The role of geological substrate for horn growth in ungulates: a case study on Alpine chamois. - Ecol. Evol. 27: 145-163.

Ciuti, S. et al. 2012. Human selection of elk behavioural traits in a landscape of fear.Proc. R. Soc. B. 279: 4407-4416.

Clutton-Brock, T. H. and Sheldon, B. C. 2010. Individuals and populations: the role of long-term, individual-based studies of animals in ecology and evolutionary biology.Trends Ecol. Evol. 25: 562-573.

Coltman, D. W. et al. 2002. Age-dependent sexual selection in bighorn rams. - Proc. R. Soc. B. 269: 165-172.

Coltman, D. W. et al. 2003. Undesirable evolutionary consequences of trophy hunting. Nature 426: 655-658.

Douhard, M. et al. 2013. Variation in adult body mass of roe deer: early environmental conditions influence early and late body growth of females. - Ecology 94: 1805-1814.

Douhard, M et al. 2016. Changes in horn size of Stone's sheep over four decades correlate with trophy hunting pressure. - Ecol. Appl. 26: 309-321.

Elton, C. S. 1924. Periodic fluctuations in the numbers of animals: their causes and effects. - J. Exp. Biol. 2: 119-163.

Fandos, P. 1995. Factors affecting horn growth in male Spanish ibex (Capra pyrenaica). - Mammalia 59: 229-235.

Feder, C. et al. 2008. Never too late? Consequences of late birthdate for mass and survival of bighorn lambs. - Oecologia 156: 773-781.

Festa-Bianchet, M. 2003. Exploitative wildlife management as a selective pressure for life-history evolution of large mammals. - In: Festa-Bianchet, M. and Apollonio, M. (eds.), Animal behavior and wildlife conservation. Island Press, pp. 191-207. 
Festa-Bianchet, M. et al. 1996. The development of sexual dimorphism: seasonal and lifetime mass changes in bighorn sheep. - Can. J. Zool. 74: 330-342.

Festa-Bianchet, M. et al. 2004. Relative allocation to horn and body growth in bighorn rams varies with resource availability. - Behav. Ecol.15: 305-312.

Festa-Bianchet, M. et al. 2014. Decrease in horn size and increase in age of trophy sheep in Alberta over 37 years. - J. Wildl. Manag. 78: 133-141.

Garel, M. et al. 2007. Selective harvesting and habitat loss produce long-term lifehistory changes in a mouflon population. - Ecol. Appl. 17: 1607-1618.

Giacometti, M. et al. 2002. Ambient temperature in spring affects horn growth in male alpine ibexes. - J. Mammal. 83: 245-251.

Grosbois, V. et al. 2008. Assessing the impact of climate variation on survival in vertebrate populations. - Biol. Rev. 83: 357-399.

Hadfield, J. D. 2010. MCMC methods for multi-response generalized linear mixed models: the MCMCglmm R Package. - J. Stat. Soft. 33: 1-22.

Hallett, T. B. et al. 2004. Why large-scale climate indices seem to predict ecological processes better than local weather. - Nature 430: 71-75.

Hebblewhite, M. 2005. Predation by wolves interacts with the North Pacific Oscillation (NPO) on a western North American elk population. - J. Anim. Ecol. 74: 226-233. 
Hegel, T. M. et al. 2010. Seasonal effects of Pacific-based climate on recruitment in a

predator-limited large herbivore. - J. Anim. Ecol. 79: 471-482.

Hemming, J. E. 1969. Cemental deposition, tooth succession, and horn development as criteria of age in Dall sheep. - J. Wildl. Manag. 33: 552-558.

Houle, D. et al. 2011. Measurement and meaning in biology. - Q. Rev. Biol. 86: 3-34.

Hurrell, J. W. 1995. Decadal trends in the North Atlantic Oscillation: regional temperatures and precipitation. - Science 269: 676-679.

Janeiro, M. J. et al. in press. Towards robust evolutionary inference with integral projection models. - J. Evol. Biol.

Jensen, H. et al. 2006. Environmental influence and cohort effects in a sexual ornament in the house sparrow, Passer domesticus. - Oikos 114: 212-224.

Jorgenson, J. T. et al. 1997. Effects of age, sex, disease and density on survival of bighorn sheep. - Ecology 78: 1019-1032.

Jorgenson, J. T. et al. 1998. Effects of population density on horn development in bighorn rams. - J. Wildl. Manag. 62: 1011-1020.

Knape, J. and de Valpine, P. 2011. Effects of weather and climate on the dynamics of animal population time series. - Proc. R. Soc. B. 278: 985-992.

'This article is protected by copyright. All rights reserved.' 
Krebs, C. J. and Berteaux, D. 2006. Problems and pitfalls in relating climate variability to population dynamics. - Clim. Res. 32: 143-149.

Leclerc, M. et al. 2016. Can hunting data be used to estimate unbiased population parameters? A case study on brown bears. - Biol. Lett. 12: 20160197.

Loehr, J. et al. 2010. The role of phenotypic plasticity in responses of hunted thinhorn sheep ram horn growth to changing climate conditions. - J. Evol. Biol. 23: 783-790.

Loison, A. et al. 1999. Body mass and winter mortality in red deer calves:

disentangling sex and climate effects. - Ecography 22: 20-30.

Lourdais, O. et al. 2004. Climate affects embryonic development in a viviparous snake, Vipera aspis. - Oikos 104: 551-560.

Marcil-Ferland, D. et al. 2013. Despite catch-up, prolonged growth has detrimental fitness consequences in a long-lived vertebrate. - Am. Nat. 182: 775-785.

Malo, A. F. et al. 2005. Antlers honestly advertise sperm production and quality. - Proc. R. Soc. B. 272: 149-157.

Mahoney, S. P. et al. 2011. Morphological change in Newfoundland caribou: Effects of abundance and climate. - Rangifer 31: 21-34.

Mantua, N. J. et al. 1997. A Pacific interdecadal climate oscillation with impacts on salmon production. - Bulletin of the American Meteorological Society 78: 1069-1079.

Martin, J. G. A. and Pelletier, F. 2011. Measuring growth patterns in the field: effects of sampling regime and methods on standardized estimates. - Can. J. Zool 89: 529-537.

Martin, A. M. et al. 2013. Male mating competitiveness and age-dependent relationship between testosterone and social rank in bighorn sheep. - Behav. Ecol. Sociobiol. 67: 919-928. 
Martínez-Jauregui, M. et al. 2009. Are local weather, NDVI and NAO consistent determinants of red deer weight across three contrasting European countries? - Glob. Change Biol. 15: 1727-1738.

Møller, A. and Jennions, M. D. 2002. How much variance can be explained by ecologists and evolutionary biologists? - Oecologia 132: 492-500.

Myneni, R. B. et al. 1997. Increased plant growth in the northern high latitudes from 1981 to $1991 .-$ Nature 386: 698-702.

Mysterud, A. et al. 2001. Nonlinear effects of large-scale climatic variability on wild and domestic herbivores. - Nature 410: 1096-1099.

Mysterud, A. et al. 2005. Climate-dependent allocation of resources to secondary sexual traits in red deer. - Oikos 111: 245-252.

Nakagawa, S. and Schielzeth, H. 2010. Repeatability for Gaussian and non-Gaussian data: a practical guide for biologists. - Biol. Rev. 85: 935-956.

Nakagawa, S. and Schielzeth, H. 2013. A general and simple method for obtaining R ${ }^{2}$ from generalized linear mixed-effects model. - Methods Ecol. Evol. 4: 133-142.

Nielsen, A. et al. 2012. Are responses of herbivores to environmental variability spatially consistent in alpine ecosystems? - Glob. Change Biol. 18: 3050-3062.

Ozgul, A. et al. 2010. Coupled dynamics of body mass and population growth in response to environmental change. - Nature 466: 482-485.

Pelletier, F. et al. 2007. Selection on heritable seasonal plasticity of body mass. Evolution 61: 1969-1979.

Pelletier, F. et al. 2012. Data from selective harvests underestimate temporal trends in quantitative traits. - Biol. Lett. 8: 878-881.

Pelletier, F. et al. 2014. Harvest refuges do not buffer wild sheep from selective hunting. -Ecol. Evol. 4: 3375-3382.

'This article is protected by copyright. All rights reserved.' 
Pérez, J. M. et al. 2011. Reduced horn size in two wild trophy-hunted species of Caprinae. -Wildlife Biol. 17: 102-112.

Pérez-Barbería F. J. et al. 1996. Horn growth pattern in Cantabrian chamois Rupicapra pyrenaica parva: Influence of sex, location and phaenology. - Acta Theriologica 41: $83-92$.

Pettorelli, N. et al. 2005. The relative role of winter and spring conditions: linking climate and landscape-scale plant phenology to alpine reindeer body mass. - Biol. Lett. 1: $24-26$.

Pettorelli, N. et al. 2007. Early onset of vegetation growth vs. rapid green-up: Impacts on juvenile mountain ungulates. - Ecology 88: 381-390.

Pigeon, G. et al. 2016. Intense selective hunting leads to artificial evolution in horn size. Evol. Appl. 9: 521-530.

Pinheiro, J. C. and Bates, D. M. 2000. Mixed-effects models in S and S-PLUS. Statistics and computing. - Springer-Verlag.

Portier, C. et al. 1998. Effects of density and weather on survival of bighorn sheep lambs (Ovis canadensis). - J. Zool. 245: 271-278.

Post, R. and Stenseth, N. C. 1999. Climatic variability, plant phenology, and northern ungulates. - Ecology 80: 1322-1339.

Rioux-Paquette, E. et al. 2011. Sex-differential effects of inbreeding on overwinter survival, birth date and mass of bighorn lambs. - J. Evol. Biol. 24: 121-131.

Rivrud, I. M et al. 2013. Hunter selection and long-term trend (1881-2008) of red deer trophy sizes in Hungary. - J. Appl. Ecol. 50: 168-180.

'This article is protected by copyright. All rights reserved.' 
Robinson, M. R. et al. 2006. Live fast, die young: trade-offs between fitness

components and sexually antagonistic selection on weaponry in Soay sheep.Evolution 60: 2168-2181.

Rughetti, M. and Festa-Bianchet, M. 2011. Seasonal changes in sexual dimorphism in Northern chamois (Rupicapra rupicapra). - J. Zool. 284: 257-264.

Rughetti, M. and Festa-Bianchet, M. 2012. Effects of spring-summer temperatures on body mass of chamois. - J. Mammal. 93: 1301-1307.

Schmidt, K. T. et al. 2001. Antler length of yearling red deer is determined by population density, weather and early life-history. - Oecologia 127: 191-197.

Seydack, A. H. et al. 2012. Climate and vegetation in a semi-arid savanna: development of a climate-vegetation response model linking plant metabolic performance to climate and the effects on forage availability for large herbivores. - Koedoe 54: 1-12.

Skalski, J. R. et al. 1993. Testing the significance of individual- and cohort-level covariates in animal survival studies. - In: Lebreton, J.-D. and North, P. M. (eds.), Marked individuals in the study of bird populations. Birkhäuser, pp. 9-28.

Smith, B. L. 1998. Antler size and winter mortality of elk: effects of environment, birth year, and parasites. - J. Mammal. 79: 1038-1044.

Stenseth, N. C. and Mysterud, A. 2005. Weather packages: finding the right scale and composition of climate in ecology. - J. Anim. Ecol. 74: 1195-1198.

Stenseth, N. C. et al. 2002. Ecological effects of climate fluctuations. - Science 297: $1292-1296$.

Stige, L. C. 2006. The effect of climate variation on agro-pastoral production in Africa.

'This article is protected by copyright. All rights reserved.' 
Proc. Natl Acad. Sci. USA 103: 3049-3053.

Tafani, M. et al. 2013. Decreasing litter size of marmots over time: a life history response to climate change? - Ecology 94: 580-586.

Toïgo, C. et al. 1999. Cohort affects growth of males but not females in alpine ibex (Capra ibex ibex). - J. Mammal. 80: 1021-1027.

Toïgo, C. et al. 2013. Alpine ibex males grow large horns at no survival cost for most of their lifetime. - Oecologia 173: 1261-1269.

Van de Pol, M. et al. 2013. Problems with using large-scale oceanic climate indices to

compare climatic sensitivities across populations and species. - Ecography 36: 249255.

Vanpé, C. et al. 2007. Antler size provides an honest signal of male phenotypic quality in roe deer. - Am. Nat. 169: 481-493.

Von Hardenberg, A. et al. 2004. Horn growth but not asymmetry heralds the onset of senescence in male Alpine ibex (Capra ibex). - J. Zool. 263: 425-432.

Wilson, A. J. et al. 2010. An ecologist's guide to the animal model. - J. Anim. Ecol. 79: $13-26$.

\section{Supplementary material}

Supplementary material (Appendix oik.XXXXX at $<$ www.oikosjournal.org/readers/appendix >). Appendix 1-6. 


\section{Table Legends}

Table 1. Effects of weather or climate variables on horn growth of wild bovid males.

\begin{tabular}{|c|c|c|c|c|c|}
\hline Species & Type of data & $\begin{array}{l}\text { N. of } \\
\text { years }\end{array}$ & Variables & Effect & References \\
\hline Alpine ibex & Harvest & 10 & temperature March-May & $(+)$ & $\begin{array}{l}\text { Giacometti et al. } \\
2002\end{array}$ \\
\hline Alpine ibex & Harvest & 48 & temperature March-May & $(+)$ & $\begin{array}{l}\text { Büntgen et al. } \\
2014\end{array}$ \\
\hline Alpine ibex & Harvest & 48 & snow cover January-May & $(-)$ & $\begin{array}{l}\text { Büntgen et al. } \\
2014\end{array}$ \\
\hline Alpine ibex & Capture & 12 & temperature April-June & $(-)$ & Toïgo et al. 1999 \\
\hline Alpine ibex & $\begin{array}{l}\text { skull } \\
\text { recovery }\end{array}$ & $?$ & precipitation May-July & $(+)$ & $\begin{array}{l}\text { von Hardenberg et } \\
\text { al. } 2004\end{array}$ \\
\hline Alpine ibex & $\begin{array}{l}\text { skull } \\
\text { recovery }\end{array}$ & $?$ & $\begin{array}{l}\text { temperature November- } \\
\text { April }\end{array}$ & $(+)$ & $\begin{array}{l}\text { von Hardenberg et } \\
\text { al. } 2004\end{array}$ \\
\hline $\begin{array}{l}\text { Spanish ibex } \\
\text { Capra } \\
\text { pyrenaica }\end{array}$ & $\begin{array}{l}\text { skull } \\
\text { recovery }\end{array}$ & 5 & $\begin{array}{l}\text { drought index June- } \\
\text { September }\end{array}$ & $(-)$ & Fandos 1995 \\
\hline $\begin{array}{l}\text { Dall sheep } \\
\text { Ovis dalli } \\
\text { dalli }\end{array}$ & Capture & $?$ & precipitation March-May & $(+)$ & Bunnell 1978 \\
\hline Dall sheep & Harvest & 42 & $\begin{array}{l}\text { principal component based } \\
\text { on temperature, } \\
\text { precipitation and PDO in } \\
\text { April-May }\end{array}$ & (?) & Loehr et al. 2010 \\
\hline $\begin{array}{l}\text { Alpine } \\
\text { chamois } \\
\text { Rupicapra } \\
\text { rupicapra }\end{array}$ & Harvest & 5 & snow cover November-April & $(-)$ & $\begin{array}{l}\text { Chirichella et al. } \\
2013 \S\end{array}$ \\
\hline $\begin{array}{l}\text { Alpine } \\
\text { chamois }\end{array}$ & Harvest & 5 & precipitation April-May & $(+)$ & $\begin{array}{l}\text { Chirichella et al. } \\
2013\end{array}$ \\
\hline $\begin{array}{l}\text { Alpine } \\
\text { chamois }\end{array}$ & Harvest & 5 & temperature March-May & $(-)$ & $\begin{array}{l}\text { Chirichella et al. } \\
2013\end{array}$ \\
\hline $\begin{array}{l}\text { Alpine } \\
\text { chamois }\end{array}$ & Harvest & 5 & temperature in July & $(-)$ & $\begin{array}{l}\text { Chirichella et al. } \\
2013\end{array}$ \\
\hline $\begin{array}{l}\text { Alpine } \\
\text { chamois }\end{array}$ & Harvest & 5 & $\begin{array}{l}\text { Temperature in December- } \\
\text { February }\end{array}$ & $(+)$ & $\begin{array}{l}\text { Chirichella et al. } \\
2013\end{array}$ \\
\hline $\begin{array}{l}\text { Cantabrian } \\
\text { chamois } \\
\text { Rupicapra } \\
\text { pyrenaica } \\
\text { parva } \\
\end{array}$ & Harvest & 9 & $\begin{array}{l}\text { Precipitation in the previous } \\
\text { year }\end{array}$ & $(+)$ & $\begin{array}{l}\text { Pérez-Barberìa et } \\
\text { al. } 1996\end{array}$ \\
\hline
\end{tabular}

I only the first annual increment was considered. § only the two first annual increments were used.

'This article is protected by copyright. All rights reserved.' 
Table 2. Correlation matrix among local weather, Pacific Decadal Oscillation (PDO) and bighorn sheep population density at Ram Mountain, Canada, between 1972 and 2013: Pearson's $r$ below the diagonal; P-value of a $t$ test for H0: $r=0$ above the diagonal. Significant correlations are in bold. 'Temp' and 'Prec' stand for local temperature and precipitation.

\begin{tabular}{|c|c|c|c|c|c|c|c|c|c|c|}
\hline Covariate & $\mathrm{PDO}_{\text {spring }}$ & $\mathrm{PDO}_{\text {winter }}$ & $\mathrm{PDO}_{\text {summer }}$ & Temp $_{\text {spring }}$ & Temp $_{\text {winter }}$ & Temp $_{\text {summer }}$ & Prec $_{\text {spring }}$ & Prec $_{\text {winter }}$ & Prec $_{\text {summer }}$ & Density \\
\hline $\mathrm{PDO}_{\text {spring }}$ & & $<0.001$ & $<0.001$ & 0.02 & 0.36 & 0.95 & 0.60 & 0.21 & 0.77 & 0.03 \\
\hline $\mathrm{PDO}_{\text {winter }}$ & 0.77 & & 0.003 & 0.02 & 0.10 & 0.80 & 0.33 & 0.13 & 0.59 & 0.62 \\
\hline $\mathrm{PDO}_{\text {summer }}$ & 0.67 & 0.44 & & 0.23 & 0.86 & 0.55 & 0.74 & 0.77 & 0.93 & 0.002 \\
\hline Temp $_{\text {spring }}$ & 0.38 & 0.37 & 0.19 & & 0.005 & 0.25 & 0.26 & 0.32 & 0.28 & 0.37 \\
\hline Temp $_{\text {winter }}$ & 0.14 & 0.26 & -0.03 & 0.43 & & 0.13 & 0.99 & 0.001 & 0.99 & 0.12 \\
\hline Temp $_{\text {summer }}$ & -0.01 & -0.04 & -0.10 & 0.20 & 0.25 & & 0.42 & 0.60 & 0.10 & 0.11 \\
\hline Prec $_{\text {spring }}$ & 0.08 & 0.16 & -0.05 & -0.18 & -0.00 & -0.14 & & 0.97 & 0.54 & 0.96 \\
\hline Prec $_{\text {winter }}$ & -0.21 & -0.26 & -0.05 & -0.17 & -0.49 & -0.10 & 0.01 & & 0.36 & 0.11 \\
\hline Prec $_{\text {summer }}$ & 0.05 & 0.09 & 0.01 & 0.19 & -0.00 & -0.28 & 0.11 & -0.18 & & 0.68 \\
\hline Density & 0.34 & 0.08 & 0.46 & 0.15 & -0.24 & -0.27 & -0.01 & 0.27 & 0.07 & \\
\hline
\end{tabular}

'This article is protected by copyright. All rights reserved.' 
Table 3. Effects of local weather, climate and population density on annual horn growth of male bighorn sheep aged 0-3 years, 1972 to 2013. 'Temp' and 'Prec' stand for local temperature and precipitation. PDO is the Pacific Decadal Oscillation. The population density by climate/weather interactions are noted *. Effects of covariates were tested with an analysis of deviance (ANODEV). $\mathrm{F}_{\text {ndf,ddf }}$ represents the F statistic of ANODEV with its associated P-value. Statistically significant effects are in bold $(\mathrm{P}<0.05)$. We standardized variables and included year as a random effect to obtain parameter estimates.

\begin{tabular}{|c|c|c|c|}
\hline Parameters & $\mathrm{F}_{\text {ndf,ddf }}$ & P-value & Estimate $\pm \mathrm{SE}$ \\
\hline $\begin{array}{l}\text { a) Weather and } \\
\text { density effects }\end{array}$ & & & \\
\hline Temp $_{\text {spring }} *$ Density & $0.24_{1,36}$ & 0.63 & $0.011 \pm 0.013$ \\
\hline Temp $_{\text {spring }}$ & $9.65_{1,37}$ & 0.003 & $0.054 \pm 0.010$ \\
\hline Prec $_{\text {spring }} *$ Density & $1.24_{1,34}$ & 0.27 & $-0.024 \pm 0.011$ \\
\hline Prec $_{\text {spring }}$ & $0.40_{1,35}$ & 0.53 & $-0.013 \pm 0.010$ \\
\hline Temp $_{\text {summer }} *$ Density & $2.48_{1,32}$ & 0.13 & $0.037 \pm 0.012$ \\
\hline Temp $_{\text {summer }}$ & $0.46_{1,33}$ & 0.50 & $0.014 \pm 0.010$ \\
\hline Prec $_{\text {summer }} *$ Density & $<0.01_{1,30}$ & 0.98 & $5.43 .10 \times 10^{-4} \pm 1.22 \times 10^{-2}$ \\
\hline Prec $_{\text {summer }}$ & $0.74_{1,31}$ & 0.40 & $-0.017 \pm 0.010$ \\
\hline Temp $_{\text {winter }} *$ Density & $0.10_{1,38}$ & 0.75 & $0.005 \pm 0.008$ \\
\hline Temp $p_{\text {winter }}$ & $1.46_{1,39}$ & 0.23 & $0.021 \pm 0.009$ \\
\hline $\operatorname{Prec}_{\text {winter }} *$ Density & $0.01_{1,32}$ & 0.92 & $0.002 \pm 0.010$ \\
\hline $\operatorname{Prec}_{\text {winter }}$ & $0.45_{1,33}$ & 0.51 & $-0.014 \pm 0.009$ \\
\hline Density & $8.32_{1,40}$ & 0.006 & $-0.059 \pm 0.010$ \\
\hline $\begin{array}{l}\text { b) Climate and } \\
\text { density effects }\end{array}$ & & & \\
\hline $\mathrm{PDO}_{\text {winter }} *$ Density & $0.23_{1,38}$ & 0.63 & $-0.009 \pm 0.010$ \\
\hline
\end{tabular}




\begin{tabular}{llll}
\hline $\mathrm{PDO}_{\text {winter }}$ & $3.40_{1,39}$ & 0.07 & $0.032 \pm 0.009$ \\
$\mathrm{PDO}_{\text {spring }}$ * Density & $4.23_{1,38}$ & 0.04 & $-0.037 \pm 0.010$ \\
$\mathrm{PDO}_{\text {summer }}$ * Density & $10.00_{1,38}$ & 0.003 & $-0.051 \pm 0.008$ \\
\hline
\end{tabular}

'This article is protected by copyright. All rights reserved.' 


\section{Figure Legends}

Fig 1. Temporal trends (linear or quadratic) in local weather, Pacific Decadal Oscillation (PDO) and bighorn sheep population density between 1972 and 2013 at Ram Mountain, Canada. Regression lines from linear models are shown when statistically significant (see supplementary Appendix 1).
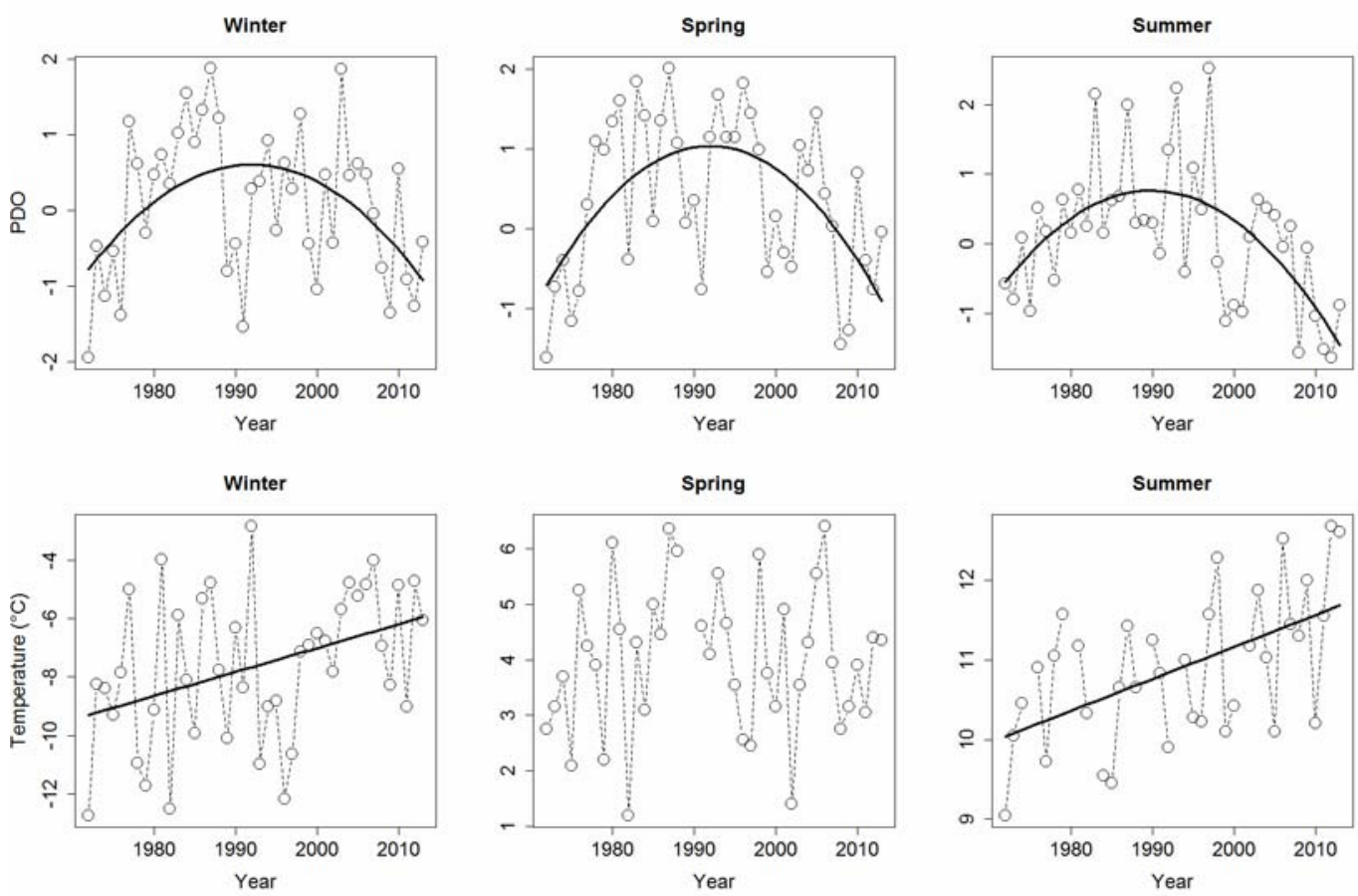

'This article is protected by copyright. All rights reserved.' 

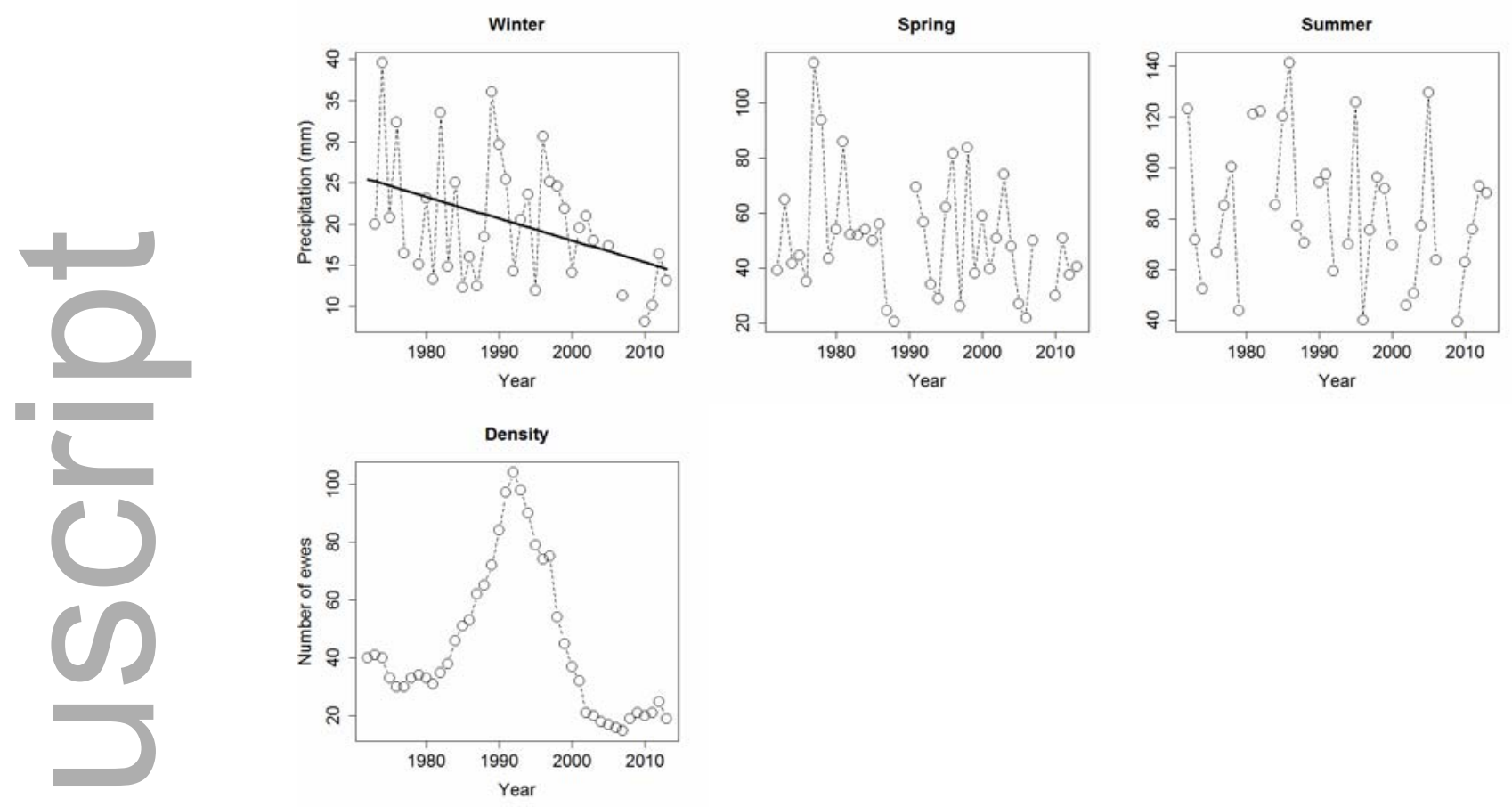

'This article is protected by copyright. All rights reserved.' 
Fig. 2. Effect of spring temperature on annual horn growth of male bighorn sheep aged 0-3 years. Filled circles correspond to average residual horn growth $( \pm \mathrm{SE})$ after controlling for the age and density effects.

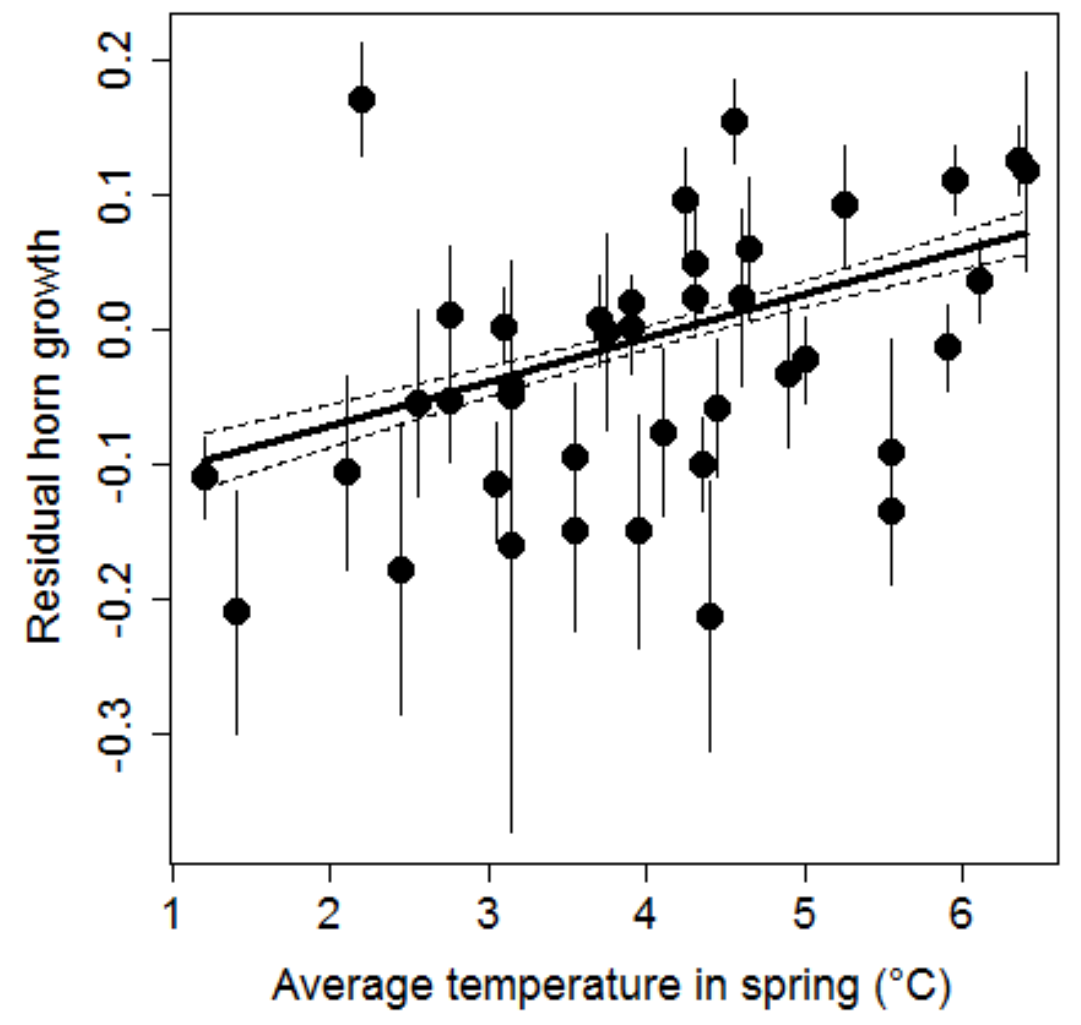

'This article is protected by copyright. All rights reserved.' 
Fig. 3. Interactive effects of the Pacific Decadal Oscillation (PDO) in spring and population density on annual horn growth of male bighorn sheep aged 0-3 years after controlling for the age. A) Density fitted as a continuous variable. B) Density fitted as a two-level factor: lower than the median population size (black circles and line), equal to or greater than the median population size (grey circles and line). Circles correspond to average residual horn growth $( \pm \mathrm{SE})$; solid and dotted lines represent the predictions and associated SE of the model.

A)

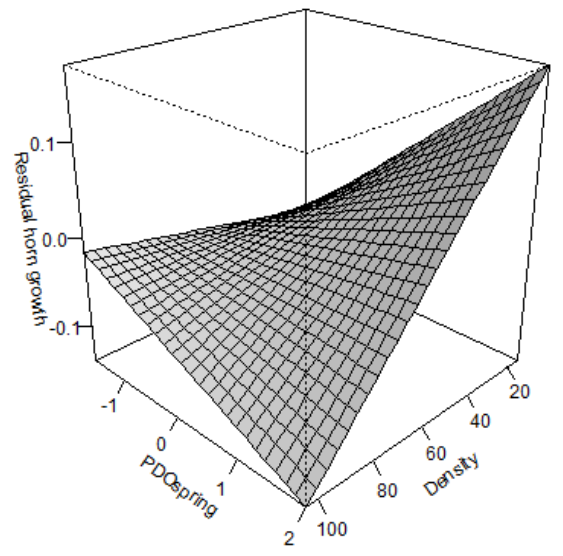

B)

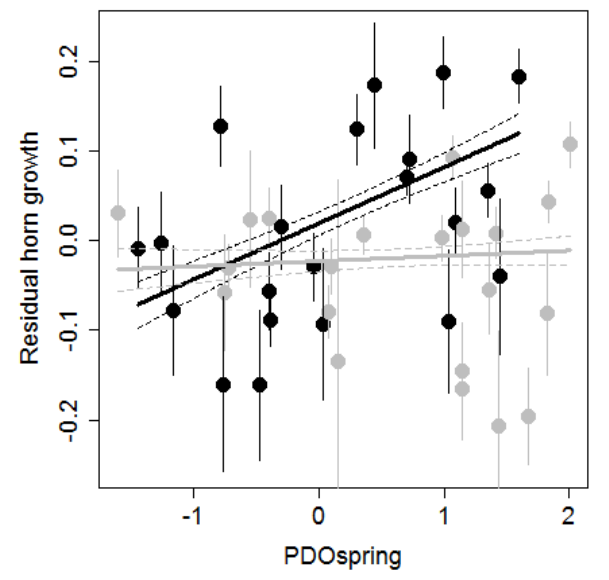

'This article is protected by copyright. All rights reserved.' 
Fig. 4. Allometric relationship between annual horn growth and summer mass gain of male bighorn sheep aged 0-3 years as a function of environmental conditions experienced that year. Population density and $\mathrm{PDO}_{\text {summer }}$ were standardized to a range of 0 to 1 to build an environmental index, defined as the sum of population density, $1-$ $\mathrm{PDO}_{\text {summer }}$ and the product of $1-\mathrm{PDO}_{\text {summer }}$ and density $\left(\mathrm{PDO}_{\text {summer }}\right.$ had a positive effect on horn growth whereas density had a negative effect). A) Environmental index fitted as a continuous variable (higher values indicated poor environmental conditions). B) Environmental index fitted as a two-level factor: less than the median (good conditions; black circles and line; slope $=0.20 \pm 0.13, \mathrm{P}=0.11$ ), equal to or greater than the median (poor conditions; grey circles and line; slope $=0.66 \pm 0.12, \mathrm{P}<0.001$ ). Circles represent individual data, solid and dotted lines represent the predictions and associated SE of the model.

A)

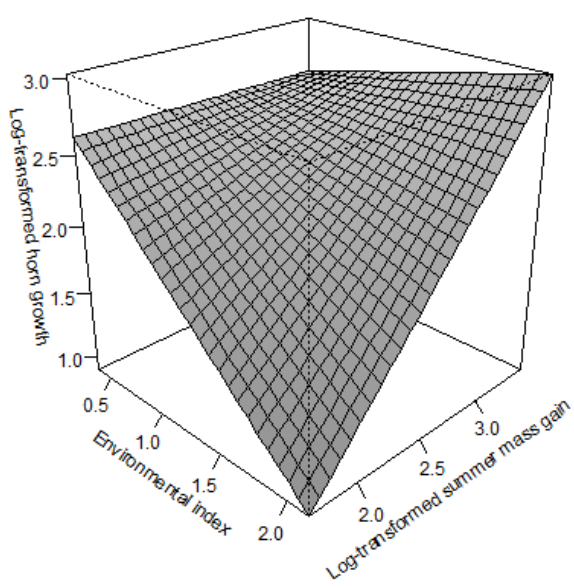

'This article is protected by copyright. All rights reserved.' 
B)

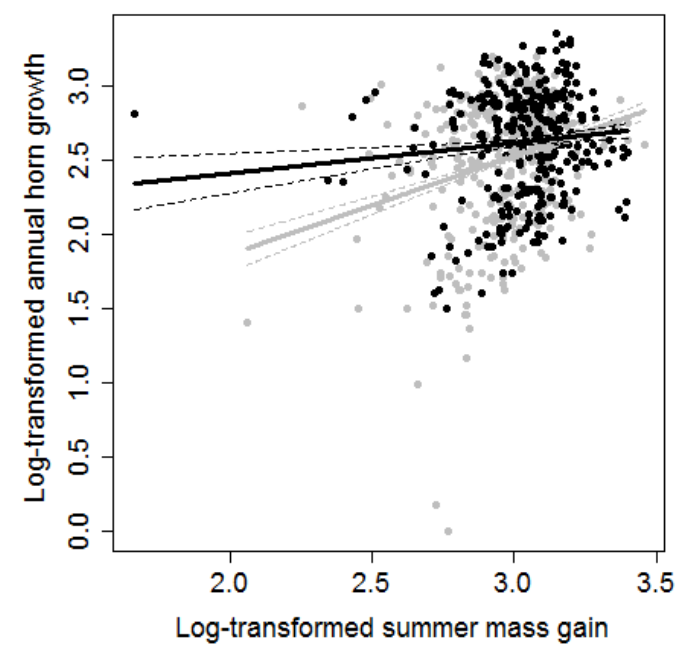

'This article is protected by copyright. All rights reserved.' 


\section{University Library}

\section{- M M N E R VA A gateway to Melbourne's research publications}

Minerva Access is the Institutional Repository of The University of Melbourne

Author/s:

Douhard, M;Pigeon, G;Festa-Bianchet, M;Coltman, DW;Guillemette, S;Pelletier, F

Title:

Environmental and evolutionary effects on horn growth of male bighorn sheep

Date:

2017-07-01

Citation:

Douhard, M., Pigeon, G., Festa-Bianchet, M., Coltman, D. W., Guillemette, S. \& Pelletier, F. (2017). Environmental and evolutionary effects on horn growth of male bighorn sheep. OIKOS, 126 (7), pp.1031-1041. https://doi.org/10.1111/oik.03799.

Persistent Link:

http://hdl.handle.net/11343/292354 